\title{
Safety, pharmacodynamics, and pharmacokinetics of multiple oral doses of delta-9-tetrahydrocannabinol in older persons with dementia
}

\author{
Amir I. A. Ahmed - Geke A. H. van den Elsen • \\ Angela Colbers • Cornelis Kramers • David M. Burger • \\ Marjolein A. van der Marck • Marcel G. M. Olde Rikkert
}

Received: 16 November 2014 / Accepted: 14 February 2015/Published online: 11 March 2015

(C) The Author(s) 2015. This article is published with open access at Springerlink.com

\begin{abstract}
Rationale Data on safety, pharmacodynamics, and pharmacokinetics of tetrahydrocannabinol (THC) are lacking in dementia patients.

Methods In this randomized, double-blind, placebo-controlled, crossover trial, we evaluated the safety, pharmacodynamics, and pharmacokinetics of THC in ten patients with dementia (mean age $77.3 \pm 5.6$ ). For 12 weeks, participants randomly received oral THC (weeks 1-6, $0.75 \mathrm{mg}$; weeks $7-12,1.5 \mathrm{mg}$ ) or placebo twice daily for 3 days, separated by a 4-day washout period.
\end{abstract}

Amir I. A. Ahmed and Geke A. H. van den Elsen contributed equally to this work.

A. I. A. Ahmed $(\bowtie)$

Department of Psychogeriatric Medicine, Vincent van Gogh Institute, Overloonseweg 4, 5804 AV Venray, The Netherlands

e-mail: amirahmed1@hotmail.com

A. I. A. Ahmed - G. A. H. van den Elsen · M. A. van der Marck • M. G. M. Olde Rikkert

Department of Geriatric Medicine and Radboud Alzheimer Centre,

Radboud University Medical Center, Nijmegen, The Netherlands

A. I. A. Ahmed · C. Kramers

Department of Pharmacology and Toxicology, Radboud University

Medical Center, Nijmegen, The Netherlands

A. Colbers $\cdot$ D. M. Burger

Department of Pharmacy, Radboud University Medical Center,

Nijmegen, The Netherlands

C. Kramers

Department of Internal Medicine, Radboud University Medical

Center, Nijmegen, The Netherlands

C. Kramers

Department of Pharmacy, Canisius Wilhelmina Hospital,

Nijmegen, The Netherlands
Results Only 6 of the 98 reported adverse events were related to THC. Visual analog scale (VAS) feeling high, VAS external perception, body sway-eyes-open, and diastolic blood pressure were not significantly different with THC. After the 0.75-mg dose, VAS internal perception (0.025 units; $95 \%$ CI $0.010-0.040)$ and heart rate (2 beats/min; $95 \%$ CI 0.4 3.8) increased significantly. Body sway-eyes-closed increased only after $1.5 \mathrm{mg}\left(0.59^{\circ} / \mathrm{s} ; 95 \%\right.$ CI $\left.0.13-1.06\right)$. Systolic blood pressure changed significantly after both doses of THC $(0.75 \mathrm{mg},-7 \mathrm{mmHg}, 95 \% \mathrm{CI}-11.4,-3.0 ; 1.5 \mathrm{mg}$, $5 \mathrm{mmHg}, 95 \%$ CI 1.0-9.2). The median $T_{\max }$ was $1-2 \mathrm{~h}$, with THC pharmacokinetics increasing linearly with increasing dose, with wide interindividual variability ( $\mathrm{CV} \%$ up to $140 \%)$. The mean $C_{\max }(\mathrm{ng} / \mathrm{mL})$ after the first dose $(0-6 \mathrm{~h})$ was $0.41(0.18-0.90)$ for the $0.75-\mathrm{mg}$ dose and $1.01(0.53$ 1.92) for the $1.5-\mathrm{mg}$ dose. After the second dose (6-24 h), the $C_{\max }$ was $0.50(0.27-0.92)$ and $0.98(0.46-2.06)$, respectively. Conclusions THC was rapidly absorbed and had dose-linear pharmacokinetics with considerable interindividual variation. Pharmacodynamic effects, including adverse events, were minor. Further studies are warranted to evaluate the pharmacodynamics and efficacy of higher THC doses in older persons with dementia.

Keywords Tetrahydrocannabinol (THC) · Safety · Pharmacodynamics $\cdot$ Pharmacokinetics

\section{Introduction}

In recent years, there has been increased interest in the medical applications of delta-9-tetrahydrocannabinol (THC), the main psychoactive cannabinoid of the cannabis plant (Cannabis sativa L.). A number of studies have demonstrated its 
effectiveness in the management of clinical conditions that are very common in older people, such as neuropsychiatric symptoms (e.g., agitation and aggression) in dementia, pain (e.g., neuropathic and spasticity in multiple sclerosis), and anorexia (Frytak et al. 1979; Sallan et al. 1980; Campbell et al. 2001; Lynch and Campbell 2011).

These therapeutic effects of THC are mediated primarily by two cannabinoid receptors: CB1 and CB2 (Devane et al. 1988; Matsuda et al. 1990; Munro et al. 1993). CB1 receptors are mainly expressed in the basal ganglia, cerebellum, hippocampus, hypothalamus, and dorsal horn (Pertwee 2006), and CB2 receptors are primarily found on immune cells and tumor cells (Pertwee et al. 2010). THC also interacts with other receptors and neurotransmitters in the brain, such as acetylcholine, dopamine, serotonin, gamma-aminobutyric acid, glutamate, norepinephrine, prostaglandins, and opioid peptides (Baker et al. 2003). These broad and complex interactions underlie the potential pharmacological effects of THC as multitarget drug candidate for the management of behavior, mood, pain, and anorexia in patients with dementia. Oral, fixed-dose THC-based drugs have recently been developed. For example, dronabinol $\left(\right.$ Marinol ${ }^{\circledR}$ ) and nabilone $\left(\right.$ Cesamet $\left.^{\circledR}\right)$ have been approved in North America and some European countries for appetite stimulation in AIDS-related anorexia, chemotherapy-induced nausea/vomiting, and pain. Namisol ${ }^{\circledR}$ is the most recently developed THC-based formulation in tablet form but has not yet gained marketing approval (Klumpers et al. 2012).

Unfortunately, preapproval clinical trials of oral THC excluded old persons from participation or did not include sufficient numbers, and most recent studies that included older participants did not perform separate analyses for the older subgroup (Ahmed et al. 2014b; van den Elsen et al. 2014, Dronabinol prescribing information 2014). Studies of the potential effectiveness of THC in older individuals should include assessment of its safety, and especially in individuals with dementia, many of whom are frail and vulnerable (Ahmed et al. 2014b). To date, only four small studies have investigated the safety and efficacy of THC as treatment for the neuropsychiatric symptoms of dementia (Volicer et al. 1997; Walther et al. 2006, 2011; Woodward et al. 2014). All studies found THC to be effective and safe in older people with dementia, but as the studies were either not randomized or included a limited number of patients, it is not possible to draw firm conclusions about the safe and effective use of THC in these individuals. Furthermore, none of the studies investigated the pharmacokinetics of THC in this population. We found only one study in the literature that evaluated plasma THC concentrations (peak levels only) in older individuals (age 51-78 years), but these individuals were not demented (Carroll et al. 2004). Drug pharmacokinetics and pharmacodynamics in older people may be altered by age-related physiological changes, multiple comorbidities, or use of other medications. Aging is accompanied by an increase in adipose tissue, a decrease in lean body mass, and a decrease in total body water (Corsonello et al. 2010), changes which increase the volume of distribution of lipophilic drugs such as THC. Moreover, a decrease in hepatic blood flow and the slower metabolism of older individuals can slow the elimination of lipophilic drugs, thereby potentially increasing exposure and side effects (Linnebur et al. 2005). In addition, dementiarelated changes in brain volume, number of neurons, and alteration in neurotransmitter sensitivity make older patients with dementia more sensitive to drugs that act on the central nervous system (Corsonello et al. 2010). Taken together, we hypothesize that the administration of THC to older people with dementia may lead to a higher THC concentrations, which subsequently lead to an increase in pharmacodynamic effects, including adverse effects, compared with previously published data for young adults (Klumpers et al. 2012) or healthy older individuals without dementia (Ahmed et al. 2014a). Understanding the pharmacodynamics and pharmacokinetics of THC in older, frail, dementia patients will help clinicians to minimize side effects and maximize benefit. Therefore, the aim of the present study was to evaluate the safety, pharmacodynamics, and pharmacokinetics of multiple oral doses of THC in older persons with dementia.

\section{Methods}

Study design and participants

This study was part of a multicenter, phase II, repeated crossover, randomized, double-blind, placebo-controlled, multipledose escalation trial of the effectiveness of THC in the treatment of the neuropsychiatric symptoms of dementia [http:// www.clinicaltrials.gov, clinical trial identifier number NCT01302340]. The study was carried out at the Radboud University Medical Center, the Netherlands. Results concerning the effectiveness of THC in the management of the neuropsychiatric symptoms of dementia will be reported separately.

Figure 1 provides an overview of the study design. The study consisted of two treatment periods, A and B. Each period consisted of three treatment blocks, resulting in a total of six blocks (period A, blocks 1 to 3; period B, blocks 4 to 6). Each block lasted 2 weeks, giving a total study duration of 12 weeks. In each block, participants received oral Namisol ${ }^{\circledR}$, a novel THC in tablet form (Klumpers et al. 2012), and matching placebo (ratio 1:1) in a double-blind crossover manner for 3 days, separated by a 4-day washout period. In period A, patients received $0.75 \mathrm{mg}$ THC twice daily, and in period $\mathrm{B}$, the dose was increased to $1.5 \mathrm{mg}$ twice daily. $\mathrm{Namisol}^{\circledR}$ and placebo were identical in appearance and taste, and both were taken under nonfasting conditions with water at 10 a.m. and 4 p.m. Study participants stayed overnight at the study site on the three 


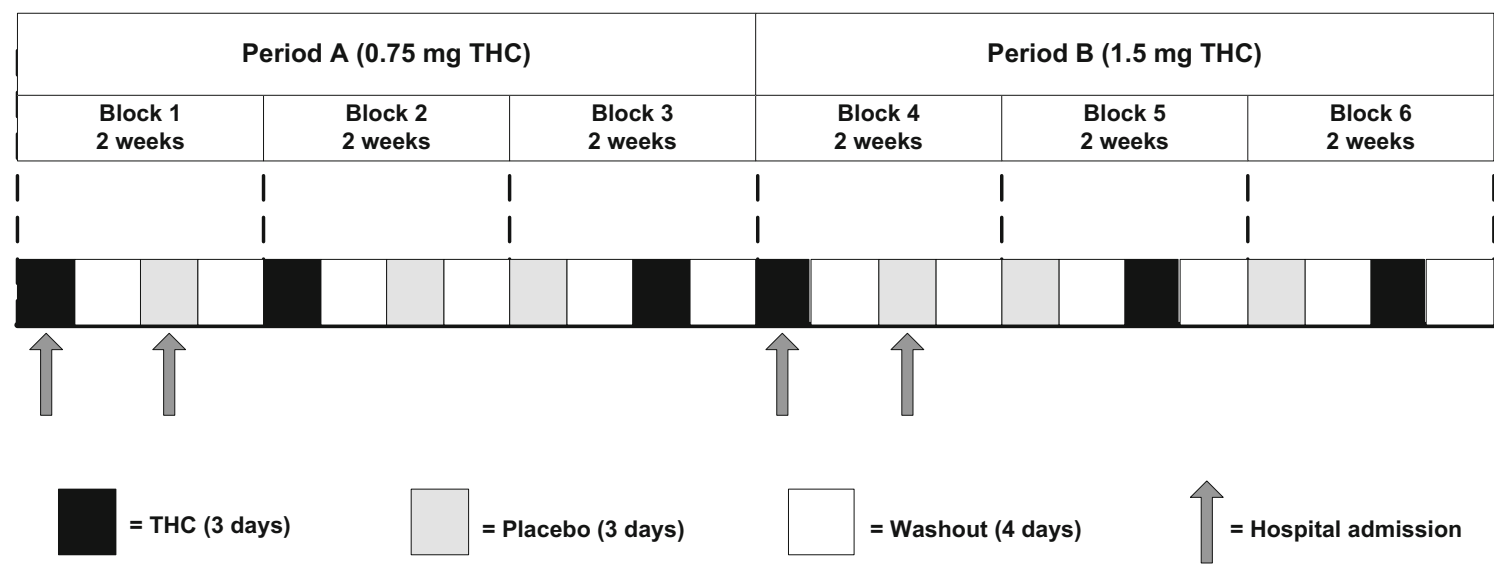

Fig. 1 Overview of the treatment period (THC and placebo were administered at random) (this is an example of random allocation of treatment)

intervention days (THC and placebo) of blocks 1 and 4 for safety reasons and to facilitate blood sampling, resulting in a total of four 3-day admissions. The randomization codes were generated by an independent pharmacist, using a computer algorithm for random numbers. Sponsor, investigators, study staff, and participants were masked to assignment.

Participants had been diagnosed with dementia type Alzheimer, vascular dementia, or mixed Alzheimer/vascular dementia, according to the National Institute of Neurological and Communicative Disorders and Stroke-Alzheimer's Disease and Related Disorders Association (NINCDSADRA) (McKhann et al. 2011) or Association Internationale pour la Recherché et l'Enseignement en Neurosciences (NINCDS-AIREN) criteria (Román et al. 1993). All patients had had clinically relevant neuropsychiatric symptoms, including at least agitation and/or aggression, in the past 30 days (Neuropsychiatric Inventory score $\geq 10$ ) (Cummings et al. 1994), and had an informal caregiver who looked after the participant at least once a week. Main exclusion criteria were major psychiatric disorders (e.g., major depression or suicidal ideation, psychosis, mania, or current delirium), current history of severe comorbidities, frequent falling due to orthostatic hypotension, history of current alcohol or drug abuse, and use of tricyclic antidepressants, opioids, or drugs from a predesigned list of cytochrome (CYP)2C9, CYP2C19, and CYP3A4 inhibitors. Written informed consent was obtained from participants (if they were able to consent and to sign) and their legal representatives. The study was approved by the local ethics committee and was performed according to the International Conference on Harmonization guideline for good clinical practice, the ethical principles of the Declaration of Helsinki, and relevant Dutch laws and regulations.

Safety and tolerability assessments

The safety and tolerability of THC were assessed subjectively and objectively, by evaluating the incidence and severity of adverse events, carrying out physical examinations, laboratory tests (hematology and clinical chemistry), and a 12-lead electrocardiogram, and assessing vital signs. The psychedelic effects were assessed with visual analogue scales (VAS), and body sway (postural stability) was measured using the SwayStar ${ }^{\mathrm{TM}}$ (see details below). During the study period, adverse events reported by patients and caregivers or observed clinically were recorded with regard to their time of onset, severity, duration, and causal relationship to study drugs. The causality was assessed by a research physician, blinded to treatment allocation, using a five-point scale: (1) unrelated, adverse event was clearly not related to the intervention; (2) unlikely, adverse event was doubtfully related to the intervention; (3) possible, adverse event may be related to the intervention; (4) probable, adverse event was likely related to the intervention; and (5) definite, adverse event was clearly related to the intervention. A serious adverse event was defined as any event that was fatal or life-threatening, that required (prolonged) hospitalization, or that resulted in persistent or significant disability or incapacity. All adverse events were coded using the Medical Dictionary for Regulatory Activities.

\section{Pharmacodynamic effects}

The scores for psychedelic effects, body sway, and vital signs were used to evaluate the pharmacodynamic effects of THC.

1. Psychedelic effects: The Bowdle VAS for psychedelic effects was used to evaluate feeling high, internal perception (inner feelings that do not correspond with reality, including mistrustful feelings), and external perception (misperception of an external stimulus or change in awareness of surroundings) (Bowdle et al. 1998; Zuurman et al. 2008). Subjects were asked to score their perceptions on a 100 -mm horizontal line, with " 0 " indicating no effect and "100" indicating extreme effect. The VAS was assessed 1 and $3 \mathrm{~h}$ after dosing on day 1 of 
weeks $1,2,7$, and 8 , in patients who were able to understand the instructions and perform the task. A recent study showed that individuals with dementia can use the VAS in a similar way to those without dementia (Arons et al. 2013).

2. Body sway: Body sway was assessed within $2 \mathrm{~h}$ of dosing on the second day of admission of weeks 1, 2, 7, and 8 . Body sway was measured ( $30 \mathrm{~s}$ eyes open and $30 \mathrm{~s}$ eyes closed) with the SwayStar ${ }^{\mathrm{TM}}$, a wireless device attached to the trunk (http://www.b2i.info/web/index.htm).

3. Vital signs: Systolic and diastolic blood pressure and heart rate were measured on day 1 of weeks $1,2,7$, and 8 , before and at 15, 30, $45 \mathrm{~min}$, and 1, 2, 3, and $4 \mathrm{~h}$ after the first dose.

Blood sampling and laboratory analysis

Venous blood samples were collected during hospital admission before and at 11, 30, $45 \mathrm{~min}$, and 1, 1.5, 2, 3, 4, and $6 \mathrm{~h}$ after the first dose, and before and at 11,30,45 min, and 1, 1.5, $2,3,4,6$, and $18 \mathrm{~h}$ after the second dose (in total covering a 24-h period). Plasma was separated by centrifugation (2000× $\left.g, 4{ }^{\circ} \mathrm{C}, 10 \mathrm{~min}\right)$ and stored at $-80{ }^{\circ} \mathrm{C}$ until analysis. After unblinding, blood samples collected in the THC treatment period were analyzed at the Analytisch Biochemisch Laboratorium b.v. (Assen, the Netherlands), using liquid chromatography with tandem-mass spectrometer detection. The lower limit of quantification was $0.1 \mathrm{ng} / \mathrm{mL}$ for $\mathrm{THC}$ and its active metabolite 11-OH-THC. The analysis was performed using a validated assay according to good laboratory practice standards (Guidance for Industry: Bioanalytical Method Validation 2001; Viswanathan et al. 2007).

\section{Pharmacokinetic analysis}

Noncompartmental analysis was performed using Phoenix WinNonlin software version 6.3 (Certara, L.P./Pharsight Ltd) to determine the pharmacokinetics of THC and 11-OH-THC. The following pharmacokinetic parameters were calculated for the 24-h period: terminal half-life $\left(t_{1 / 2}\right)$, area under the curve (AUC) from 0 to $24 \mathrm{~h}\left(\mathrm{AUC}_{0-24 \mathrm{~h}}\right)$, and apparent clearance $\left(\mathrm{CL} / \mathrm{F}\right.$, being the dose $\left./ \mathrm{AUC}_{0-24 \mathrm{~h}}\right)$. The following parameters were calculated for the two curves (curve 1, 0-6 h after the first THC dose; curve 2, 6-24 h after the second dose) separately: the maximum plasma concentration $\left(C_{\max }\right)$, the time to reach $C_{\max }\left(T_{\max }\right)$, AUC from 0 to $6 \mathrm{~h}\left(\mathrm{AUC}_{0-6 \mathrm{~h}}\right)$, and AUC from 6 to $24 \mathrm{~h}\left(\mathrm{AUC}_{6-24 \mathrm{~h}}\right)$, using the linear-up logdown trapezoidal rule. Concentration-time graphs were plotted for the two doses. Geometric means plus $95 \%$ confidence intervals were calculated for each pharmacokinetic parameter for each dose. The coefficients of variation $(\mathrm{CV} \%)$ of the geometric means were calculated to describe the interindividual variability in pharmacokinetic parameters. The geometric mean ratio (GMR) plus $90 \%$ confidence intervals of $\mathrm{AUC}_{0-24 \mathrm{~h}}, \mathrm{CL} / \mathrm{F}$, and $t_{1 / 2}$ of the 1.5 -mg dose versus the 0.75 -mg dose were also calculated.

Statistical analysis

This study is descriptive and explorative, and therefore, no sample size calculation was performed. Descriptive statistics were used to describe the study population. Continuous data are expressed as means \pm standard deviation $( \pm \mathrm{SD})$, and categorical data are expressed as frequencies and percentages. The compliance to study medication was calculated for the whole study sample. Differences in adverse event rates between THC and placebo were compared by Wilcoxon signed ranks test. The VAS scores were clustered and log-transformed, and the scores are expressed as units, as described previously (Zuurman et al. 2008; Klumpers et al. 2012). The $90 \%$ range of pitch velocity (anterior-posterior movements) scores of the SwayStar ${ }^{\mathrm{TM}}$ was used to analyze body sway. Scores are given in degrees per second. The VAS, body sway, and vital signs scores were analyzed in relation to the THC dose, using linear mixed models with participants as a random effect. Statistical analyses were performed using SAS ${ }^{\mathrm{TM}}$ software, version 9.2 (SAS Institute, Inc., Cary, NC, USA).

\section{Results}

\section{Participants}

The data of ten patients with dementia were analyzed. Their demographic characteristics are summarized in Table 1. The mean age of participants was $77.3 \pm 5.6$ years; their mean body mass index was $25.7 \pm 2.7 \mathrm{~kg} / \mathrm{m}^{2}$; seven participants were men; and nine participants had Alzheimer's disease. Overall, treatment compliance to study medication was high, and almost $98 \%$ (THC $99 \%$; placebo $97.5 \%$ ) of the trial drugs were taken.

\section{Safety and tolerability assessments}

All participants completed the study as scheduled. In general, THC was safe and well tolerated by these older individuals with dementia. In total, 98 adverse events were reported during the study period. More adverse events were reported with placebo (55 adverse events) than with THC (43 adverse events) (period A, $0.75 \mathrm{mg}$ THC 21 adverse events and placebo 30 adverse events, $P=0.290$; period B, $1.5 \mathrm{mg}$ THC 22 adverse events and placebo 25 adverse events, $P=0.435$ ).

Thirteen $(13 \%)$ of the reported adverse events were considered to be possibly $(n=12)$ or probably $(n=1)$ related to study drugs (THC and placebo). Of these, only six adverse 
Table 1 Baseline demographic characteristics

\begin{tabular}{|c|c|}
\hline Characteristics & $n=10$ \\
\hline Male, $n(\%)$ & $7(70)$ \\
\hline Age, mean (SD) (years) & $77.3(5.6)$ \\
\hline BMI, mean (SD) $\left(\mathrm{kg} / \mathrm{m}^{2}\right)$ & $25.7(2.7)$ \\
\hline \multicolumn{2}{|l|}{ Ethnicity, $n$} \\
\hline Caucasian & 9 \\
\hline Other & 1 \\
\hline \multicolumn{2}{|l|}{ Type of dementia, $n$} \\
\hline Alzheimer & 9 \\
\hline Vascular & 0 \\
\hline Mixed & 1 \\
\hline MMSE score, mean (SD) & $18.5(6.0)$ \\
\hline Smokers, $n$ & 0 \\
\hline \multicolumn{2}{|l|}{ Comorbidities, $n$} \\
\hline Cardiac rhythm disorder & 5 \\
\hline Hypertension & 5 \\
\hline Ventricular hypertrophy & 3 \\
\hline Diabetes & 2 \\
\hline Electrolyte disturbances & 2 \\
\hline Kidney function disorder & 2 \\
\hline Vitamins deficiency & 2 \\
\hline Hypercholesterolemia & 1 \\
\hline Liver function disorder & 1 \\
\hline Orthostatic hypotension & 1 \\
\hline \multicolumn{2}{|l|}{ Medications, $n$} \\
\hline Antidementia drugs $\mathrm{s}^{\mathrm{a}}$ & 16 \\
\hline Memantine & 9 \\
\hline Rivastigmine & 5 \\
\hline Galantamine & 2 \\
\hline Antihypertensives ${ }^{\mathrm{a}}$ & 11 \\
\hline Anticoagulants & 4 \\
\hline Blood glucose lowering drugs & 3 \\
\hline Antidepressants & 1 \\
\hline Antiepileptics & 1 \\
\hline Antipsychotics & 1 \\
\hline Proton pump inhibitor & 1 \\
\hline Other & 12 \\
\hline
\end{tabular}

${ }^{\text {a }}$ Some participants used a combination of drugs within the same medication group

events ( $6 \%$ of total adverse events) were considered to be (possibly) related to THC, two with $0.75 \mathrm{mg}$ (dizziness and fatigue in one patient each), and four with $1.5 \mathrm{mg}$ (agitation in three patients and fatigue in one patient). All were mild and transitory in nature. There were no THC-related serious adverse events. THC treatment was not associated with changes in the patients' physical state, laboratory test results (hematology and clinical chemistry), or ECG parameters (e.g., QT and RR intervals).
Pharmacodynamic results

THC did not cause significant changes in scores for VAS feeling high, VAS external perception, body sway with eyes open, and diastolic blood pressure (Table 2). The 0.75-mg dose, but not the $1.5-\mathrm{mg}$ dose, was associated with a statistically significant increase in VAS internal perception scores (0.025 units, $95 \%$ CI $0.010,0.040)$. The $1.5-\mathrm{mg}$ dose, but not the $0.75-\mathrm{mg}$ dose, significantly increased body sway with eyes closed $\left(0.59^{\circ} / \mathrm{s}, 95 \%\right.$ CI $\left.0.13,1.06\right)$. The $0.75-\mathrm{mg}$ dose significantly decreased systolic blood pressure $(-7.2 \mathrm{mmHg}$, $95 \% \mathrm{CI}-11.4,-3.0)$, whereas the $1.5-\mathrm{mg}$ dose significantly increased systolic blood pressure $(5.1 \mathrm{mmHg}, 95 \%$ CI 1.0 , 9.2). Heart rate increased significantly after the administration of the 0.75 -mg dose only ( 2 beats $/ \mathrm{min}, 95 \%$ CI $0.4,3.8$ ). None of the changes in the pharmacodynamic parameters was associated with an adverse event.

Pharmacokinetic results

Pharmacokinetic parameters are summarized in Tables 3 and 4. The data of one person were excluded because no blood samples were taken after the first THC dose of $0.75 \mathrm{mg}$, and only a limited amount of blood was taken after the second dose. Although one subject was non-Caucasian, his pharmacokinetic data were within the range of the others.

The median $T_{\max }$ was between 1 and $2 \mathrm{~h}$ and was not dose dependent. For the $0.75-\mathrm{mg}$ dose, the median $T_{\max }$ was reached $1.5 \mathrm{~h}$ (range $0.75-3.08$ ) after the first dose and $2 \mathrm{~h}$ (range 0.5-2.07) after the second dose; for the 1.5-mg dose, the median $T_{\max }$ was reached $1 \mathrm{~h}$ (range $0.5-2.2$ ) after the first dose and $2 \mathrm{~h}$ (range 0.5-3.02) after the second dose (Table 3). Plasma concentrations of THC and 11-OH-THC increased linearly with increasing dose, but there was considerable interindividual variation in plasma concentrations and hence in pharmacokinetic parameters (Fig. 2). For THC, $C_{\max }$ and AUC CV\% ranged from 90 to $140 \%$, and for $11-\mathrm{OH}-\mathrm{THC}$ from $38 \%$ to $62 \%$. The elimination phase of THC was faster than that of 11-OH-THC.

The geometric mean ratio of the THC $\mathrm{AUC}_{0-24 \mathrm{~h}}$ versus the 11-OH-THC AUC $0-24 \mathrm{~h}$ was 1.7 (95\% CI 1.1, 2.9) and 1.9 (95\% CI 1.0, 3.6) for the 0.75 - and 1.5 -mg doses, respectively. Individual THC and 11-OH-THC AUCs are presented in Fig. 3. Two participants had a high THC exposure after the 0.75-mg dose. Their $\mathrm{AUC}_{0-24 \mathrm{~h}}$ was 8.0 and $8.4 \mathrm{ng} \mathrm{h} / \mathrm{mL}$ compared with a value ranging between 0.9 and $2.7 \mathrm{ng} \mathrm{h} /$ $\mathrm{mL}$ in the other participants. Three participants had a high exposure after the $1.5-\mathrm{mg}$ dose. Their $\mathrm{AUC}_{0-24 \mathrm{~h}}$ was 13 , 19 , and $20 \mathrm{ng} \mathrm{h} / \mathrm{mL}$ compared with a value ranging between 1.2 and $4.1 \mathrm{ng} \mathrm{h} / \mathrm{mL}$ in the other participants. One participant had a greater increase in THC AUC after the 1.5 -mg dose than the other participants; the AUC GMR for this subject was 7 
Table 2 Pharmacodynamic effects of THC doses

\begin{tabular}{lll}
\hline Parameters $^{\mathrm{a}}$ & THC $0.75 \mathrm{mg}$ versus placebo $(n=10)$ & THC 1.5 mg versus placebo $(n=10)$ \\
\hline VAS feeling high $(\mathrm{U})^{\mathrm{b}}$ & $-0.010[95 \% \mathrm{CI}-0.037 ; 0.017] ; P=0.47$ & $0.002[95 \% \mathrm{CI}-0.024 ; 0.028] ; P=0.90$ \\
VAS external perception $(\mathrm{U})^{\mathrm{b}}$ & $0.012[95 \% \mathrm{CI}-0.005 ; 0.029] ; P=0.16$ & $-0.014[95 \% \mathrm{CI}-0.031 ; 0.003] ; P=0.11$ \\
VAS internal perception $(\mathrm{U})^{\mathrm{b}}$ & $0.025[95 \% \mathrm{CI} 0.010 ; 0.040] ; P=0.001^{\mathrm{c}}$ & $-0.002[95 \% \mathrm{CI}-0.014 ; 0.010] ; P=0.75$ \\
Body sway, eyes open $(\%)$ & $0.37[95 \% \mathrm{CI}-1.31 ;+2.10] ; P=0.63$ & $0.26[95 \% \mathrm{CI}-0.91 ; 1.44] ; P=0.67$ \\
Body sway, eyes closed $(\%)$ & $0.61[95 \% \mathrm{CI}-0.63 ;+1.85] ; P=0.30$ & $0.59[95 \% \mathrm{CI}+0.13 ;+1.06] ; P<0.05^{\mathrm{c}}$ \\
Systolic blood pressure $(\mathrm{mmHg})$ & $-7.2[95 \% \mathrm{CI}-11.4 ;-3.0] ; P<0.001^{\mathrm{c}}$ & $5.1[95 \% \mathrm{CI} 1.0 ; 9.2] ; P<0.05^{\mathrm{c}}$ \\
Diastolic blood pressure $(\mathrm{mmHg})$ & $0.2[95 \% \mathrm{CI}-2.0 ; 2.3] ; P=0.86$ & $-0.1[95 \% \mathrm{CI}-2.2 ; 2.0] ; P=0.92$ \\
Heart rate $($ beats $/ \mathrm{min})$ & $2.1[95 \% \mathrm{CI} 0.4 ; 3.8] ; P<0.05^{\mathrm{c}}$ & $-0.4[95 \% \mathrm{CI}-2.0 ; 1.3] ; P=0.66$ \\
\hline
\end{tabular}

${ }^{\text {a }}$ All parameters are presented as mean $[95 \%$ confidence intervals $(\mathrm{CI})] ; P$ values

${ }^{\mathrm{b}}$ Log-transformed visual analog scale (VAS) [scores in $\mathrm{mm}+2$ ]. Scores are given in units (U)

${ }^{\mathrm{c}}$ Statistically significant $P$ values $(\alpha=0.05)$

compared with 1.7-2.5 (range) for the other participants. The same was seen for 11-OH-THC, but less pronounced (Fig. 3).

\section{Discussion}

\section{Safety and tolerability}

Older people with dementia and physical comorbidity could greatly benefit from the therapeutic application of cannabinoids. Recent studies have demonstrated that low doses of THC are effective in protecting the brain from neuroinflammation-induced cognitive damage (Aso et al. 2012; Aso and Ferrer 2014; Fishbein-Kaminietsky et al. 2014). Although THC-based drugs have recently been approved for clinical use, there are only few data on their safety in older individuals with dementia. Our data demonstrate that THC doses of 0.75 and $1.5 \mathrm{mg}$ twice daily are safe and well tolerated by older individuals with dementia. Only 6 of the 98 reported adverse events were related to THC treatment. All adverse events were mild and resolved spontaneously without any intervention. Our findings are in line with previously published studies showing that THC doses up to $5 \mathrm{mg} /$ day are safe to use in older individuals with dementia (Volicer et al. 1997; Walther et al. 2006, 2011). It is important to note that the safety data presented in this study are based upon short-term use of THC in older subject with dementia. Further studies are warranted to evaluate the long-term use of THC in this population.

\section{Pharmacodynamics}

Overall, THC had fewer pharmacodynamic effects, including adverse events, than we had expected for frail older individuals with dementia, based on the effects reported by Klumpers et al. (2012) in young adults (mean age 21 years). We found no statistically significant changes in participants' feeling high, external perception, body sway with the eyes open,

Table 3 Pharmacokinetic parameters of THC and 11-OH-THC

\begin{tabular}{|c|c|c|c|c|}
\hline \multirow[t]{2}{*}{ Parameters ${ }^{\mathrm{a}}$} & \multicolumn{2}{|l|}{$\mathrm{THC}$} & \multicolumn{2}{|l|}{ 11-OH-THC } \\
\hline & $0.75 \mathrm{mg}(n=9)$ & $1.5 \mathrm{mg}(n=10)$ & $0.75 \mathrm{mg}(n=9)$ & $1.5 \mathrm{mg}(n=10)$ \\
\hline $\mathrm{AUC}_{0-24}(\mathrm{ng} \mathrm{h} / \mathrm{mL})$ & $2.21[96](1.19-4.12)$ & $4.66[122](2.35-9.25)$ & $3.86[46](2.76-5.42)$ & $8.92[50](6.35-12.54)$ \\
\hline CL/F (L/h) & $0.68[96](0.36-1.26)$ & 0.64 [122] $(0.32-1.28)$ & $0.39[46](0.28-0.54)$ & $0.34[50](0.24-0.47)$ \\
\hline$t_{1 / 2}(\mathrm{~h})$ & $5.08[39](3.81-6.77)$ & $5.06[37](3.92-6.54)$ & 7.80 [31] (6.19-9.82) & $6.77[61](4.54-10.10)$ \\
\hline$C_{\max }$ curve $1(\mathrm{ng} / \mathrm{mL})$ & $0.41[138](0.18-0.90)$ & $1.01[112](0.53-1.92)$ & $0.56[62](0.36-0.87)$ & $1.21[61](0.90-1.64)$ \\
\hline$T_{\max }$ curve $1(\mathrm{~h})$ & $1.5(0.75-3.08)$ & $1.01(0.5-2.2)$ & $1.5(0.75-3.08)$ & $1.76(0.75-3.02)$ \\
\hline$C_{\max }$ curve $2(\mathrm{ng} / \mathrm{mL})$ & $0.50[94](0.27-0.92)$ & $0.98[140](0.46-2.06)$ & $0.55[54](0.37-0.82)$ & $1.21[44](0.90-1.64)$ \\
\hline$T_{\max }$ curve $2(\mathrm{~h})$ & $2(0.5-2.07)$ & $2(0.5-3.02)$ & $1.00(0.5-2.07)$ & $1.76(0.75-3.02)$ \\
\hline $\mathrm{AUC}_{0-6 \mathrm{~h}}$ curve $1(\mathrm{ng} \mathrm{h} / \mathrm{mL})$ & $0.88[124](0.42-1.85)$ & $2.01[136](0.97-4.17)$ & 1.37 [45] (0.99-1.90) & 3.35 [55] (2.31-4.84) \\
\hline $\mathrm{AUC}_{6-24 \mathrm{~h}}$ curve $2(\mathrm{ng} \mathrm{h} / \mathrm{mL})$ & $0.98[90](0.54-1.77)$ & $2.04[115](1.06-3.94)$ & 1.47 [38] (1.11-1.95) & $3.46[47](2.51-4.78)$ \\
\hline
\end{tabular}

${ }^{a}$ All parameters are presented as geometric mean [coefficients of variation \%] (95\% confidence intervals)

$A U C$ area under the curve, $C L / F$ oral clearance, $t_{1 / 2}$ half-life, $C_{\max }$ peak plasma concentration, $T_{\max }$ time to reach $C_{\max }$ 
Table 4 Geometric mean ratios of THC and 11-OH-THC

\begin{tabular}{lll}
\hline Parameters & THC & $11-\mathrm{OH}-\mathrm{THC}$ \\
\hline $\mathrm{AUC}_{0-24}(\mathrm{ng} \mathrm{h} / \mathrm{mL})$ & $2.40(1.83-3.16)$ & $2.25(1.82-2.77)$ \\
$\mathrm{CL} / \mathrm{F}(\mathrm{L} / \mathrm{h})$ & $0.83(0.63-1.10)$ & $0.89(0.72-1.10)$ \\
$t_{1 / 2}(\mathrm{~h})$ & $1.00(0.72-1.39)$ & $0.88(0.58-1.34)$
\end{tabular}

Geometric mean ratio 1.5 versus $0.75 \mathrm{mg}$ over one dosing interval $(90 \%$ $\mathrm{CI})$

and diastolic blood pressure after THC. The changes in internal perception, body sway with eyes closed, systolic blood pressure, and heart rate after THC were not considered clinically relevant, as they were small and were not associated with adverse events. The current findings are consistent with our previous findings from a phase 1 study of Namisol ${ }^{\circledR}$ in healthy older individuals without dementia ( $n=11$, mean age 72 years) (Ahmed et al. 2014a).

Pharmacokinetics

On the basis of the AUC and $C_{\max }$ values, THC has linear pharmacokinetics in elderly individuals with dementia, showing a doubling of the AUC and $C_{\max }$ with doubling dose from
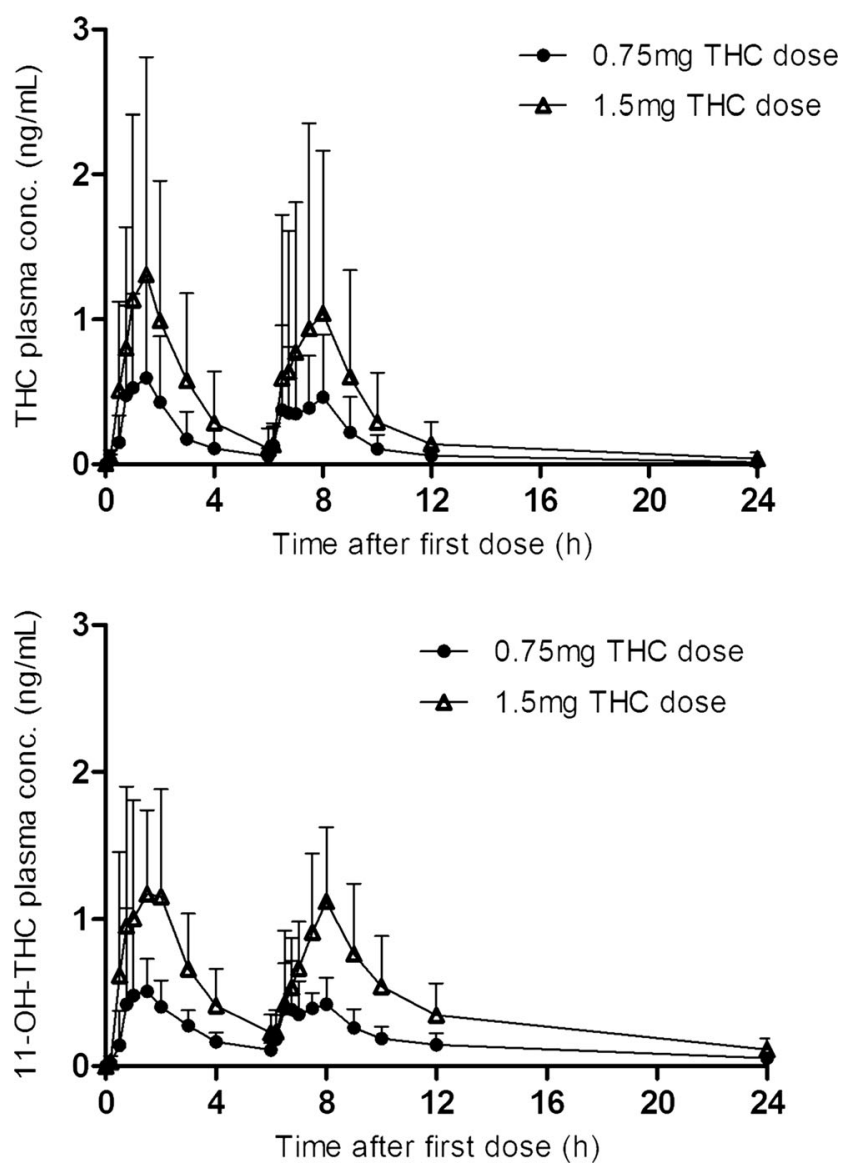

Fig. 2 The mean concentration time profiles of THC and 11-OH-THC for both the 0.75 - and $1.5-\mathrm{mg}$ doses over $24 \mathrm{~h}$
THC AUC $0-24 \mathrm{~h}$

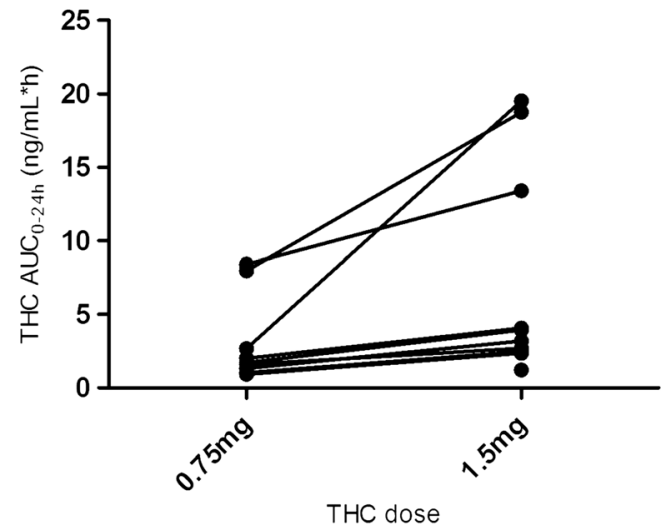

11-OH-THC AUC $0-24 \mathrm{~h}$

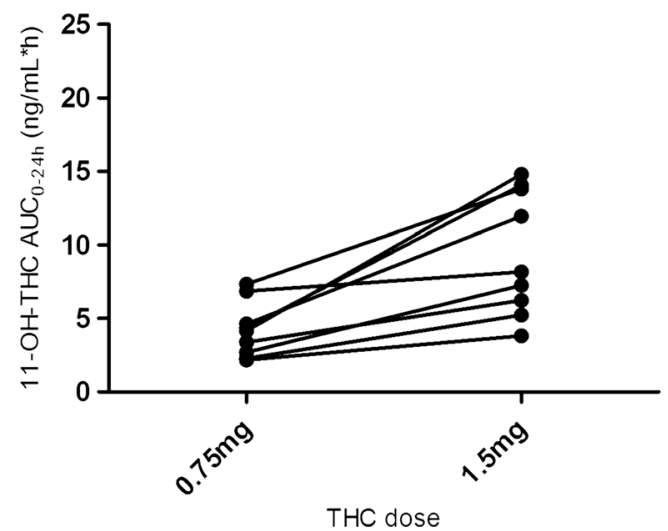

Fig. 3 Individual pharmacokinetic parameter graphs

0.75 to $1.50 \mathrm{mg}$. However, there was considerable interindividual variation in plasma concentrations of THC and 11-OHTHC, which is in line with our data from a phase 1 study involving healthy older individuals (Ahmed et al. 2014a), and with the results of studies involving individuals of different ages (Carroll et al. 2004; Joerger et al. 2012; Klumpers et al. 2012). The median $T_{\max }$ was reached $1-2 \mathrm{~h}$ after THC dosing, as has been previously reported for healthy older individuals without dementia (Ahmed et al. 2014a). In contrast, Klumpers et al. (2012) reported a shorter $T_{\max }$ between 39 and $56 \mathrm{~min}$ in young adults after $\mathrm{Namisol}^{\circledR}$ administration. The $\mathrm{AUC}_{0-6} \mathrm{~h}$ for older persons with dementia was two times higher than would be expected on the basis of data for young adults administered Namisol ${ }^{\circledR}$ (individual concentrations were retrieved and $\mathrm{AUC}_{0-6 \mathrm{~h}}$ was calculated) (Klumpers et al. 2012). A possible explanation for the discrepancies in $T_{\max }$ and $\mathrm{AUC}_{0-6 \mathrm{~h}}$ is that, in the current study, THC was taken in nonfasting state, whereas Klumpers et al. (2012) administered THC to fasting young adults. Stott et al. (2013), in their investigation of the effect of food on the absorption and bioavailability of cannabinoids, found that the $T_{\max }$ for THC was reached about $2-2.5 \mathrm{~h}$ later in the fed state than in the fasting state: the mean AUC and $C_{\max }$ for THC and 11-OH-THC 
were onefold and threefold higher, respectively, in the fed state than in the fasting state. Age-related factors, such as delayed gastric emptying time, decreased splanchnic blood flow, decreased gastrointestinal motility, and decreased absorption surface, could also affect the absorption and bioavailability of THC in older individuals. It was not possible to compare our data with data from other pharmacokinetic studies involving older individuals with dementia because we did not find any relevant studies that reported data separately for this group.

The relatively high THC exposure in two participants seems to have been due to a diminished metabolism of THC to 11-OH-THC, as in both participants the 11-OH-THC/THC ratio of the $\mathrm{AUC}_{0-24 \mathrm{~h}}$ was less than 1 for both doses, whereas it was almost 2 in the other participants. However, the sum of 11-OH-THC plus THC $\mathrm{AUC}_{0-24 \mathrm{~h}}$ was higher in these two participants than in the other participants, but this higher THC exposure was not associated with adverse events.

Strengths and limitations

The main strengths of the current study were, first, its design. In this randomized, double-blind, placebo-controlled, repeated crossover study, study staff and participants were masked to assignment and participants served as their own control. This design strengthened the validity of the safety and pharmacodynamic data. Second, our study is the first to evaluate the pharmacokinetics and pharmacodynamics of THC in older individuals with dementia, a frail subgroup of older persons. Therefore, this study can be added to the limited literature available on this subject.

The most notable limitation is that we probably used a very low THC dose-escalation regimen, 0.75 to $1.5 \mathrm{mg}$, as only 6 of the 98 reported adverse events were related to THC treatment and the pharmacodynamic effects were in general smaller than we had expected for this subgroup of older persons. A future dose-escalation study is required to determine the maximum tolerable dosage. This will help to maximize effectiveness while keeping side effects acceptable.

\section{Conclusion}

Our findings suggest that low THC doses are safe and well tolerated by frail older persons with dementia. Oral THC was rapidly absorbed, showing dose-linear pharmacokinetics with maximum plasma concentrations being reached between 1 and $2 \mathrm{~h}$ after dosing, although there was considerable interindividual variability. Overall, THC showed smaller pharmacodynamic effects in frail older individuals than expected on the basis of data for young healthy adults. These reassuring data warrant further pharmacodynamic and efficacy studies with higher THC doses in older patients with dementia.
Acknowledgments The authors would like to kindly thank Ton B Feuth for his contribution in the data analysis.

Funding This trial was made possible by a grant from the European Union, the European Fund for Regional Development, and the Dutch province Gelderland (Grant no 2009-019329) awarded to the consortium of Echo Pharmaceuticals, the developer of Namisol ${ }^{\circledR}$, and the Radboud University Medical Center Echo Pharmaceuticals (developer) had no role in study design; data collection, analysis, or interpretation; or writing of this paper.

Conflict of interest All authors declare that they have no any conflict of interest, financial, or otherwise.

Open Access This article is distributed under the terms of the Creative Commons Attribution License which permits any use, distribution, and reproduction in any medium, provided the original author(s) and the source are credited.

\section{References}

Ahmed AI, van den Elsen GA, Colbers A, van der Marck MA, Burger DM, Feuth TB, Olde Rikkert MG, Kramers C (2014a) Safety and pharmacokinetics of oral delta-9- tetrahydrocannabinol in healthy older subjects: a randomized controlled trial. Eur Neuropsychopharmacol 24: $1475-1482$

Ahmed AI, van den Elsen GA, van der Marck MA, Olde Rikkert MG (2014b) Medicinal use of cannabis and cannabinoids in older adults: where is the evidence? J Am Geriatr Soc 62:410-411

Arons AM, Krabbe PF, van der Wilt GJ, Olde Rikkert MG, Adang EM (2013) Visual analogue scales: scale recalibration by patients with dementia and their proxies. Qual Life Res 22:979-986

Aso E, Ferrer I (2014) Cannabinoids for treatment of Alzheimer's disease: moving toward the clinic. Front Pharmacol 5:37

Aso E, Palomer E, Juvés S, Maldonado R, Muñoz FJ, Ferrer I (2012) CB1 agonist ACEA protects neurons and reduces the cognitive impairment of A PPP/PS1 mice. J Alzheimers Dis 30:439-459

Baker D, Pryce G, Giovannoni G, Thompson AJ (2003) The therapeutic potential of cannabis. Lancet Neurol 2:291-298

Bowdle TA, Radant AD, Cowley DS, Kharasch ED, Strassman RJ, RoyByrne PP (1998) Psychedelic effects of ketamine in healthy volunteers: relationship to steady-state plasma concentrations. Anesthesiology 88:82-88

Campbell FA, Tramer MR, Carroll D, Reynolds DJ, Moore RA, McQuay HJ (2001) Are cannabinoids an effective and safe treatment option in the management of pain? A qualitative systematic review. BMJ $323: 13-16$

Carroll CB, Bain PG, Teare L, Liu X, Joint C, Wroath C, Parkin SG, Fox P, Wright D, Hobart J, Zajicek JP (2004) Cannabis for dyskinesia in Parkinson disease: a randomized double-blind crossover study. Neurology 63:1245-1250

Corsonello A, Pedone C, Incalzi RA (2010) Age related pharmacokinetic and pharmacodynamic changes and related risk of adverse drug reactions. Curr Med Chem 17:571-584

Cummings JL, Mega M, Gray K, Rosenberg-Thompson S, Carusi DA, Gornbein J (1994) The Neuropsychiatric Inventory: comprehensive assessment of psychopathology in dementia. Neurology 44:23082314

Devane WA, Dysarz FA 3rd, Johnson MR, Melvin LS, Howlett AC (1988) Determination and characterization of a cannabinoid receptor in rat brain. Mol Pharmacol 34:605-613 
Dronabinol. Dronabinol prescribing information. http://www.fda.gov/ ohrms/dockets/dockets/05n0479/05N-0479-emc0004-04.pdf. Accessed 1 Jul 2014

Fishbein-Kaminietsky M, Gafni M, Sarne Y (2014) Ultralow doses of cannabinoid drugs protect the mouse brain from inflammationinduced cognitive damage. J Neurosci Res 92:1669-1677

Frytak S, Moertel CG, O'Fallon JR, Rubin J, Creagan ET, O'Connell MJ, Schutt AJ, Schwartau NW (1979) Delta-9-tetrahydrocannabinol as an antiemetic for patients receiving cancer chemotherapy A comparison with prochlorperazine and a placebo. Ann Intern Med 91:825830

Guidance for Industry: Bioanalytical Method Validation US Department of Health and Human Services, Food and Drug Administration, Center for Drug Evaluation and Research (CDER), Center for Veterinary Medicine (CVM) May 2001: http://www.fda.gov/ downloads/Drugs/Guidances/ucm070107.pdf Accessed 1 Jul 2014

Joerger M, Wilkins J, Fagagnini S, Baldinge R, Brenneisen R, Schneider U, Goldman B, Weber M (2012) Single-dose pharmacokinetics and tolerability of oral delta-9- tetrahydrocannabinol in patients with amyotrophic lateral sclerosis. Drug Metab Lett 6:102-108

Klumpers LE, Beumer TL, van Hasselt JG, Lipplaa A, Karger LB, Kleinloog HD, Freijer JI, de Kam ML, van Gerven JM (2012) Novel Delta(9)-tetrahydrocannabinol formulation Namisol ${ }^{\circledR}$ has beneficial pharmacokinetics and promising pharmacodynamic effects. Br J Clin Pharmacol 74:42-53

Linnebur SA, O'Connell MB, Wessell AM, McCord AD, Kennedy DH, DeMaagd G, Dent LA, Splinter MY, Biery JC Jr, Chang F, Jackson RC, Miller SL, Sterling T, Force AT (2005) Pharmacy practice, research, education, and advocacy for older adults. Pharmacotherapy 25:1396-1430

Lynch ME, Campbell F (2011) Cannabinoids for treatment of chronic non-cancer pain; a systematic review of randomized trials. $\mathrm{Br} \mathrm{J}$ Clin Pharmacol 72:735-744

Matsuda LA, Lolait SJ, Brownstein MJ, Young AC, Bonner TI (1990) Structure of a cannabinoid receptor and functional expression of the cloned cDNA. Nature 346:561-564

McKhann GM, Knopman DS, Chertkow H, Hyman BT, Jack CR Jr, Kawas CH, Klunk WE, Koroshetz WJ, Manly JJ, Mayeux R, Mohs RC, Morris JC, Rossor MN, Scheltens P, Carrillo MC, Thies B, Weintraub S, Phelps CH (2011) The diagnosis of dementia due to Alzheimer's disease: recommendations from the National Institute on Aging-Alzheimer's Association workgroups on diagnostic guidelines for Alzheimer's disease. Alzheimers Dement 7:263-269

Munro S, Thomas KL, Abu-Shaar M (1993) Molecular characterization of a peripheral receptor for cannabinoids. Nature 365:61-65
Pertwee RG (2006) Cannabinoid pharmacology: the first 66 years. Br J Pharmacol 147(Suppl 1):S163-S171

Pertwee RG, Howlett AC, Abood ME, Alexander SP, Di Marzo V, Elphick MR, Greasley PJ, Hansen HS, Kunos G, Mackie K, Mechoulam R, Ross RA (2010) International Union of Basic and Clinical Pharmacology LXXIX Cannabinoid receptors and their ligands: beyond $\mathrm{CB}(1)$ and $\mathrm{CB}(2)$. Pharmacol Rev 62:588-631

Román GC, Tatemichi TK, Erkinjuntti T, Cummings JL, Masdeu JC, Garcia JH, Amaducci L, Orgogozo JM, Brun A, Hofman A et al (1993) Vascular dementia: diagnostic criteria for research studies Report of the NINDS-AIREN International Workshop. Neurology 43:250-260

Sallan SE, Cronin C, Zelen M, Zinberg NE (1980) Antiemetics in patients receiving chemotherapy for cancer: a randomized comparison of delta-9-tetrahydrocannabinol and prochlorperazine. N Engl J Med 302:135-138

Stott CG, White L, Wright S, Wilbraham D, Guy GW (2013) A phase I study to assess the effect of food on the single dose bioavailability of the THC/CBD oromucosal spray. Eur J Clin Pharmacol 69:825-834

van den Elsen GA, Ahmed AI, Lammers M, Kramers C, Verkes RJ, van der Marck MA, Rikkert MG (2014) Efficacy and safety of medical cannabinoids in older subjects: a systematic review. Ageing Res Rev 14:56-64

Viswanathan C, Bansal S, Booth B (2007) Quantitative bioanalytical methods validation and implementation: best practices for chromatographic and ligand binding assays. Pharm Res 24:1962-1973

Volicer L, Stelly M, Morris J, McLaughlin J, Volicer BJ (1997) Effects of dronabinol on anorexia and disturbed behavior in patients with Alzheimer's disease. Int J Geriatr Psychiatry 12:913-919

Walther S, Mahlberg R, Eichmann U, Kunz D (2006) Delta-9tetrahydrocannabinol for nighttime agitation in severe dementia. Psychopharmacology 185:524-528

Walther S, Schupbach B, Seifritz E, Homan P, Strik W (2011) Randomized, controlled crossover trial of dronabinol, $25 \mathrm{mg}$, for agitation in 2 patients with dementia. J Clin Psychopharmacol 31: 256-258

Woodward MR, Harper DG, Stolyar A, Forester BP, Ellison JM (2014) Dronabinol for the treatment of agitation and aggressive behavior in acutely hospitalized severely demented patients with noncognitive behavioral symptoms. Am J Geriatr Psychiatry 22:415-419

Zuurman L, Roy C, Schoemaker RC, Hazekamp A, den Hartigh J, Bender JC, Verpoorte R, Pinquier JL, Cohen AF, van Gerven JM (2008) Effect of intrapulmonary tetrahydrocannabinol administration in humans. J Psychopharmacol 22:707-716 